\section{Spore-forming Bacteria in Potatoes}

IT is generally accepted by plant pathologists that no spore-forming bacterium (Bacillus) is directly responsible for disease in plants and that such as are associated with lesions are saprophytes or secondary invaders. Accounts and even detailed experiments ${ }^{1}$ have app sared from time to time attributing pathogenic powers to certain species of the subtilis group, notably $B s$. mesentericus, but these have not been confirmed.

In the spring of this year several lots of stored potato tubers affected by bacterial rot were submitted by the Ministry of Agriculture and Fisheries to me for investigation, and from one of these in which the interior had been converted into a gummy transparent mass a spore-forming bacterium was isolated. Provisionally identified as Bs. polymyxa (Prazmowski) Migula by Dr. T. Gibson of Edinburgh, this organism produces a complete rot with evolution of much gas when inoculated on to slices of fresh potato, carrots, onions, cucumber and iris stems. Bs. polymyxa was re-isolated from some of these slices and re-inoculated into a further series of slices with similar results. This has been repeated several times at temperatures varying from room temperature to $37^{\circ} \mathrm{C}$., and there can be no doubt that the spore-former $B s$. polymyxa, a normal inhabitant of soil, is pathogenic to plants under certain conditions.

Up to the present most bacterial potato rots have been ascribed to the well-known non-spore-formers, Bact. carotovorum, Bact. aroidece and Corynebacterium sepedonicum, but from the present investigation it seems evident that under certain conditions of storage potato tubers can be rotted by some species of sporeforming bacteria. The conditions under which these bacteria are able to invade tubers are only partially known and merit more extensive investigation than has hitherto been accorded them in view of the serious losses caused. Further work is proceeding.

\section{Botany School,}

Cambridge.

Aug. 22.

${ }^{2}$ Brierley, P., Phytopathology, 18, 819 (1937).

\section{Colour of Red Blood Corpuscles}

A sInate red blood corpuscle, illuminated by white light, appears yellow under the microscops. Why does it not appear pink ? I have asked distinguished zoologists, physiologists, histologists and authorities on colour-vision, but only one has given even a tentative answer, though all have agreed to the fact. The yellow appearance is mentioned by the authors of a few histological text-books, but they either make no comment or else suggest that one would expect yellowness on account of the thinness of the coloured layer. The change of colour of certain dyes on dilution is sometimes attributed to different degrees of dissociation of the dye molecule, but the yellow appearance of a single red blood corpuscle must clearly be attributed to some special phenomenon of colour-vision that is not a matter of general knowledge among biologists.

The subject is important apart from its intrinsic interest, especially in connexion with the application of chemical colour-tests to microscopical objects. It frequently happens that when a red or purple re- action is expected, a yellow appsarance is given. This happens particularly with the various aldehyde reactions for tryptophane. Test-tube experiments show a purple or purplish-red reaction, and massive protein-bodies in cells show a similar colour. The cytoplasm itself, however, generally appears yellow. in thin sections, and the interpretation is difficult. An understanding of the tendency of pale red objects to appear yellow would help in the interpretation of histochemical colour-tests applied to very minute objects, such as mitochondria and the dictyosomes of the Golgi element.

\section{Department of Zoology and Comparative Anatomy, University Museum, Oxford. Aug. I4.}

\section{JOHN R. BAKER.}

\section{Length of Life of Sperms in the Wood- louse Armadillidium vulgare Latr.}

RESULts which could only be explained by the suggestion that sperms can be stored in females of $A$. vulgare for at least a year and that sperms are still viable after this storage have already been published $^{1,2}$. Further evidence for this suggestion has now been obtained. In 1941 the two black females, $E C$ and $E K$, were mated with the red males, $J D A$ and $J D B$, respectively. Both females produced a brood in the summer of 1941 and they were both kept separate from males in the. winter of 1941--42. Nevertheless both females again produced broods in the summer of 1942, and the composition of these broods (brood 176 from female $E C$, 20 red : 17 black; and brood 175 from female $E K$, 8 red : 4 black) shows that they were not produced by parthenogenesis since red colour is due to a single dominant gene.

School of Agriculture, Cambridge.

Aug. 27.

2 Howard, J. Genet., 40, 83 (1940).

2 Howard, J. Genet., 44, 143 (1942).

\section{Ocular Muscles and Vision}

THE double function of the ocular muscles, as described in my letter in NATURE of April 10, p. 422, explains many illusions, one of which has been freely discussed without any satisfactory explanation. This refers to the apparent appearance of a moving motorcar or carriage, as if it were standing still. The eye on moving takes a fresh photograph, which is seen for an appreciable time. The decomposed visual purple is swept out of the way by the back pressure. Note the difference in appearance of a tennis or cricket ball when the eyes are still and when they are moving following the ball. A very curious example may be seen at a cinema. If, when an orator is speaking, the eyes be directed to another part of the picture and then immediately be turned back again to the orator, he will be seen quite still, with his mouth open or closed, while his voice goes on.

F. W. Edridge-Green.

45 Dollis Hill Avenue,

London, N.W.2. Aug. 3. 